Please do not remove this page

RMIT

UNIVERSITY

\title{
Development of a finite-element analysis methodology for the propagation of delaminations in composite structures
}

Orifici, Adrian; Thomson, Rodney; Degenhardt, Richard; Bisagni, Chiara; Bayandor, Javid https://researchrepository.rmit.edu.au/esploro/outputs/9921859937901341/filesAndLinks?institution=61RMIT_INST\&index=null

Orifici, A., Thomson, R., Degenhardt, R., Bisagni, C., \& Bayandor, J. (2007). Development of a finite-element analysis methodology for the propagation of delaminations in composite structures. Mechanics Of Composite Materials, 43(1), 9-28. https://doi.org/10.1007/s11029-007-0002-6

Document Version: Accepted Manuscript

Published Version: https://doi.org/10.1007/s11029-007-0002-6

Repository homepage: https://researchrepository.rmit.edu.au

(C) 2007 Springer Science+Business Media, Inc.

Downloaded On 2023/04/26 19:20:13 +1000 
Thank you for downloading this document from the RMIT Research Repository.

The RMIT Research Repository is an open access database showcasing the research outputs of RMIT University researchers.

RMIT Research Repository: http://researchbank.rmit.edu.au/

\section{Citation:}

Orifici, A, Thomson, R, Degenhardt, R, Bisagni, C and Bayandor, J 2007, 'Development of a finite-element analysis methodology for the propagation of delaminations in composite structures', Mechanics Of Composite Materials, vol. 43, no. 1, pp. 9-28.

See this record in the RMIT Research Repository at:

http://researchbank.rmit.edu.au/view/rmit:4629

Version: Accepted Manuscript

Copyright Statement: (C) 2007 Springer Science+Business Media, Inc.

Link to Published Version:

http://dx.doi.org/10.1007/s11029-007-0002-6 


\title{
Development of a Finite Element Analysis Methodology for the Propagation of Delaminations in Composite Structures
}

Adrian C. Orifici * ${ }^{1}$, Rodney S. Thomson ${ }^{2}$, Richard Degenhardt ${ }^{3}$, Chiara Bisagni ${ }^{4}$ and Javid Bayandor ${ }^{5}$

${ }^{1}$ School of Aerospace, Mechanical \& Manufacturing Engineering, Royal Melbourne Institute of Technology, GPO Box 2476V, Melbourne, Victoria, 3001, Australia.

* corresponding author: s2008675@student.rmit.edu.au

${ }^{2}$ Cooperative Research Centre for Advanced Composite Structures Limited, 506 Lorimer Street, Fishermans Bend, Victoria, 3207, Australia.

${ }^{3}$ Institute of Composite Structures and Adaptive Systems, DLR - German Aerospace Center, Lilienthalplatz 7, 38108 Braunschweig, Germany.

${ }^{4}$ Dipartimento di Ingegneria Aerospaziale, Politecnico di Milano, Via La Masa 34, 20156 Milan, Italy.

${ }^{5}$ The Sir Lawrence Wackett Aerospace Centre, School of Aerospace, Mechanical and Manufacturing Engineering, Royal Melbourne Institute of Technology, GPO Box 2476V, Melbourne, Victoria, 3001, Australia.

\begin{abstract}
Analysing the collapse of skin-stiffened structures requires capturing the critical phenomenon of skin-stiffener separation, which can be considered analogous to interlaminar cracking. This paper presents the development of a numerical approach for simulating the propagation of interlaminar cracks in composite structures. A degradation methodology was applied in MSC.Marc that involved modelling the structure with shell layers connected by user-defined multiple point constraints (MPCs). User subroutines were written that apply the Virtual Crack Closure Technique (VCCT) to determine the onset of crack growth, and modify the properties of the user-defined MPCs to simulate crack propagation. Methodologies for the release of failing MPCs are presented and are discussed with reference to the VCCT assumption of self-similar crack growth. Numerical results applying the release methodologies are then compared with experimental results for a double cantilever beam specimen. Based on this comparison, recommendations for the future development of the degradation model are made, especially with reference to developing an approach for the collapse analysis of fuselage-representative structures.
\end{abstract}

Keywords: delamination, Virtual Crack Closure Technique, double cantilever beam, propagation modelling.

\section{Introduction}

The European Commission Project COCOMAT (Improved MATerial Exploitation at Safe Design of COmposite Airframe Structures by Accurate Simulation of COllapse) is an ongoing four-year project that aims to exploit the large strength reserves of composite aerospace structures through a more accurate prediction of collapse [1-2]. Accordingly, one of the COCOMAT work-packages involves the development of degradation models capable of capturing the composite damage mechanisms that contribute to structural 
collapse. For stiffened structures in compression one of the most critical damage mechanisms leading to structural collapse is detachment of the skin and stiffener, typically initiated at a stiffener flange edge. In co-cured stiffened panels this detachment is caused by delamination growth at or near the skin-stiffener interface, and in secondary bonded panels usually involves adhesive disbonding between the skin and stiffener in addition to delamination. In order to include the effects of skin-stiffener separation in numerical analyses it is necessary to capture both the initiation and propagation of this type of damage. This paper is focused on the growth of an existing skin-stiffener separation, with the prediction of damage initiation from an intact structure to be the subject of future work.

In structures manufactured from laminated composite materials, the phenomenon of skinstiffener separation can be considered analogous to that of interlaminar cracking, for which the use of fracture mechanics to predict crack growth has become common practice over the past two decades [3-4]. This analogy is directly applicable between lamina in co-cured stiffened panels and is an approximation in the case of the adhesive layer in secondary bonded panels. In fracture mechanics analysis, the strain energy released in crack growth is compared to a threshold maximum strain energy release rate, called the interlaminar fracture toughness $G_{C}$. The strain energy release rate $G$ is typically split into three components according to the separate mechanisms of crack growth: opening (I), sliding (II) and scissoring (III), as shown in Figure 1. The strain energy release rates and fracture toughnesses in all three modes are usually applied in single-mode criteria or combined in a mixed-mode criterion to determine the onset of propagation, and these generally require curve-fitting parameters taken from experimental testing.

The Virtual Crack Closure Technique (VCCT) is one of the most commonly applied methods for determining the components of the strain energy release rate along a crack front. The VCCT approach was proposed by Rybicki and Kanninen [5] and is based on two assumptions: 1) Irwin's assumption that the energy released in crack growth is equal to the work required to close the crack to its original length, and; 2) that crack growth does not significantly alter the state at the crack tip. The use of VCCT is advantageous as it allows the strain energy release rates to be determined with simple equations from a single finite element (FE) analysis. Numerous researchers have applied VCCT to analyse the crack growth properties of pre-existing interlaminar damage in a range of structures, including fracture mechanics test specimens [6-7], bonded joints [8-9], and both co-cured and secondary bonded skin-stiffener interfaces [10-12].

Predicting the collapse of a structure taking skin-stiffener separation into account also requires the disbonded area to be grown during analysis. To date, VCCT has been limited in this respect due to the requirement of a fine mesh of the order of the ply thickness [13] and the need for complicated algorithms to monitor the shape of the crack front. An alternative approach for modelling skin-stiffener separation is with so-called cohesive elements, which are used to control the relationship between opening stresses and displacements in an interface [14-15]. Cohesive elements offer the advantages of incorporating both initiation and propagation of disbonding in such a way that damage is initiated using strength criteria and final separation is governed by fracture mechanics. However, like the VCCT approach, cohesive elements require a fine mesh to remain accurate, and can become prohibitively inaccurate when larger mesh sizes are used, which makes their application to large structures problematic. Also, the standard cohesive element formulation cannot account for an arbitrary crack front shape and so does not differentiate between mode II and III directions, and in general the exact location of the crack front can 
be difficult to define. So, in spite of its disadvantages, the VCCT approach remains attractive for application into crack growth analysis as it provides information on the exact nature of the crack front and crack growth mechanisms, and is expected to retain an acceptable degree of accuracy with larger mesh sizes.

In this paper, an approach proposed in previous work [16] based on VCCT for the propagation of interlaminar crack growth in a nonlinear FE analysis is further developed. This approach involved modelling the structure with two layers of shell elements separated by a nominal distance and joined using multiple point constraints (MPCs). At the end of every increment, the strain energy release rates are calculated using VCCT at the MPCs on the crack front. Upon satisfaction of simple single-mode criteria any failing MPCs are released, and the disbonded area is increased for the following increment. In previous work it was shown that the release of MPCs in this manner gave conservative results, as it allowed for the VCCT assumption of self-similar crack growth to be violated. New methodologies for the release of failing MPCs are presented, which attempt to better correlate the VCCT calculation with the resultant crack front created. The propagation methodologies are then compared in the analysis of a double cantilever beam (DCB) specimen. Based on comparison with the experimental results, recommendations for the future development of the degradation model are made, especially with reference to the goal of developing an approach suitable for the collapse analysis of fuselage-representative structures.

\section{Analysis}

\section{Modelling approach}

The modelling approach applied in this work for the separation of two composite layers was previously developed in Ref. [16], and is summarised in Figure 2. In this approach, two layers of shell elements are identically meshed and connected with user-defined MPCs. The shell layers are nominally coincident, though separated by a distance of $0.001 \mathrm{~mm}$ in order to differentiate between opening and closing tying forces in the MPCs. The distance of $0.001 \mathrm{~mm}$ is a compromise between using extremely small values and maintaining precision in floating-point calculations, and was validated as having negligible effect on solution accuracy in separate FE analyses. The nodes of the shell elements are offset from the element mid-plane to the interface between the two shells using "dummy" or nominally zero-stiffness layers, shown in Figure 3. Placing the nodes at this interface avoids the requirement for complicated constraint equations that are necessary for nodes modelled at the shell mid-planes. The use of dummy layers avoids the use of plate offsets, which can give inaccurate results in geometric nonlinear analyses. However, errors are introduced in the interlaminar shear distribution as shown in Figure 4, though as the magnitude of this error is proportional to the dummy layer thickness [17] in this work it was not expected to be significant. All FE models applied here were analysed with MSC.Marc v2005r2 (Marc), and pre- and post-processed with MSC.Mentat [18].

Each user-defined MPC acted on a node pair of one node from each shell layer, with the lower node of each pair arbitrarily selected as the master node. The MPCs were given one of three "states", in order to represent the different constraint conditions within the structure. State 0 was for MPCs in the intact region, state 1 for MPCs in the intact region but on the crack front or border between intact and disbonded regions, and state 2 for MPCs in the disbonded region. Intact MPCs (states 0 and 1) applied a displacement constraint and 
disbonded MPCs (state 2) applied no constraint between the two nodes. Note that only the displacements and not the rotations of the nodes were constrained, in order to maintain the correct bending of the separate shell layers, especially in the region of the crack tip. This constraint condition was validated with separate FE models of bending plates containing a disbonded region, and is also in agreement with $\mathrm{FE}$ analysis and recommendations of other researchers $[10,13]$.

User subroutines were written to control the state of the MPCs in order to increase the disbonded area during an analysis. The user subroutines were written in Fortran, and implemented in the UEDINC and UFORMS subroutines provided in Marc. Both developed user subroutines performed functions dependent on the state of each MPC, and these were kept in an internal variable called a common block. The interaction of the two user subroutines within a nonlinear analysis increment is illustrated in Figure 5.

The UEDINC user subroutine is a dummy routine provided in Marc that is called at the end of every increment in a nonlinear analysis. With reference to Figure 5, the developed UEDINC subroutine performed a loop over all user-defined MPCs to calculate the strain energy release rates at all MPCs on the disbond front (state 1) and assessed whether the interface fracture toughness had been exceeded. A separate loop was then used to change the failing MPCs to disbonded (state 2) and to change the corresponding MPCs for the new crack front. The calculation of strain energy release rate was carried out using VCCT equations described in the following section.

The UFORMS subroutine is provided within Marc to allow the definition of a user-defined MPC. The subroutine is called several times in every iteration for each user-defined MPC, and is used to provide the constraint matrix for the calling MPC. The constraint matrix is the matrix that relates the degrees of freedom of the slave node to the master node in the MPC node pair. In the developed UFORMS subroutine the internal states variable was accessed, and the MPC properties were set to either intact for MPC states 0 and 1, or disbonded for MPC state 2.

\section{Strain energy release rates}

The Virtual Crack Closure Technique is based on the Two-Step Virtual Crack Closure Technique or Crack Closure Method (CCM). In CCM crack growth is analysed with two separate finite element analyses before and after crack extension, step 1 and 2 as shown in Figure 6 for the two-dimensional case. CCM is based on Irwin's crack closure integral [19], which assumes that the energy released in crack extension is equal to the work required to close it again. From Figure 6, the force vector, F, holding the crack together is taken from step 1, and the displacement vector, $\boldsymbol{\delta}_{u}-\boldsymbol{\delta}_{l}$, between the upper and lower nodes upon crack extension is taken from step 2 . The energy release rate is calculated as the energy released (the work done in closing) divided by the area of crack surface formed, $\Delta A$. This area is the new crack surface area created as a result of the release of the crack node from step 1 to step 2 . In the two-dimensional example of Figure $6, \Delta A$ is equal to $\Delta a \cdot 1$, or the crack growth length multiplied by a unit width, but generally this does not apply and the crack growth area must be determined. The equation for $\Delta \mathbf{G}$ or vector change in strain energy release rate is given by

$$
\Delta \mathbf{G}=\frac{1}{2} \mathbf{F}\left(\boldsymbol{\delta}_{u}-\boldsymbol{\delta}_{l}\right) / \Delta A
$$


VCCT is based on the same assumption as CCM of Irwin's crack closure integral. Additionally, it is assumed that crack growth does not significantly alter the state at the crack tip, that is, the crack grows in a self-similar manner. This means that the displacements ahead of the crack tip in step 1 can be assumed to be equal to the displacements that will occur upon crack extension. This allows the calculation to be performed in a single FE analysis, which is particularly relevant here as the calculation is to be included as part of a propagation analysis.

Figure 7 shows an example FE model for VCCT created using the proposed modelling approach, with rectangular shell elements of arbitrary length and width. In this Figure, the upper and lower shell layers in the intact region are overlapping and are indistinguishable. For this type of model the VCCT equations needed to account for changes in element length in all directions. This required the correct crack surface area to be found using the appropriate nodal coordinates. Additionally, the displacements at the node ahead of the crack front were adjusted to account for changes in element lengths behind and in front of the crack front. This was done using linear interpolation, as suggested in Ref. [13], so that the VCCT equations for arbitrary shell elements are given by $[10,13]$

$$
\begin{aligned}
G_{I} & =-\frac{1}{2} \frac{1}{\Delta A} F_{\mathrm{z} 1}\left(w_{2}-w_{2^{\prime}}\right) \frac{a_{0}}{a_{2}}, \\
G_{I I} & =-\frac{1}{2} \frac{1}{\Delta A} F_{\mathrm{x} 1}\left(u_{2}-u_{2^{\prime}}\right) \frac{a_{0}}{a_{2}}, \\
G_{I I I} & =-\frac{1}{2} \frac{1}{\Delta A} F_{\mathrm{y}_{1}}\left(v_{2}-v_{2^{\prime}}\right) \frac{a_{0}}{a_{2}},
\end{aligned}
$$

where with reference to Figure 7: $G_{I}, G_{I I}, G_{I I I}$ are strain energy release rates in local mode I, II and III directions; $\Delta A$ is the virtual crack growth area; $\left\{F_{x}, F_{y}, F_{z}\right\}$, and $\{u, v, w\}$ are forces and displacements in the local $\mathrm{x}, \mathrm{y}$ and $\mathrm{z}$ directions; $a$ are distances from the crack front MPC; subscripts 0, 1 and 2 refer to values taken from MPCs of states intact, crack front and disbonded, and; 2' is the lower node of the MPC in the disbonded region. Note that these equations are for shell elements constrained to each other only by displacements with rotations left free, and as such do not include any rotations or tying moments at the crack front.

The local crack front directions were also required in order to apply VCCT to an arbitrary crack front. The method for determining the local crack front coordinate system was adapted from Ref. [13], and is illustrated in Figure 8. This approach was based on locating the neighbouring nodes on either side of the crack front, which were used to form the local mode III direction and to determine the local mode I and II directions. Using the local crack front coordinate system the forces and displacements were resolved into their correct mode I, II and III components, to reflect the true crack opening mechanisms acting locally on the crack front.

To incorporate the VCCT approach into a propagation analysis it was necessary to account for the wide variety of crack front shapes possible, shown in Figure 9. Whilst all of these crack shapes were not expected in the DCB model, for more complex models it was necessary to account for all crack growth possibilities. With reference to Figure 9, any crack front shape or crack type was defined as a crack front MPC in the centre of a 
maximum of four 4-noded shell elements. So any crack front MPC could have a maximum of four adjacent side MPCs and four diagonal MPCs. Crack types were classified according to the status of the adjacent side MPCs, and whether the MPC was on a structural edge. It was assumed that triangular elements were not used.

For each of the different crack front shapes it was necessary to define a set of displacements and areas for the VCCT calculation. The approach taken was based on applying the VCCT assumption of self-similar crack growth to the local crack front. The local crack front was defined as the central MPC with a maximum of two adjacent crack front MPCs depending on whether the central MPC was on a structural edge. Based on the propagation of the local crack front shape, the crack growth area was calculated and displacements were taken from the most appropriate of the surrounding MPCs. This is summarised in Figure 9, where in the "VCCT MPCs" column, the "displacements" MPC is the one from which displacements were taken, and the "new location" MPC is the one to which the central failing MPC was grown. This type of "locally self-similar" configuration still requires the global VCCT assumption that at all points on the crack front, crack opening displacements can be taken from the same increment as crack closing forces. The only exception to the locally selfsimilar configuration was for crack growth at a convex corner, crack type 10 in Figure 9, where the area was based on the growth of only the central failing MPC.

\section{Propagation modelling}

The propagation method is the way in which the crack front was advanced once the crack growth criteria were satisfied. Four different propagation methods were implemented, in order to compare the sensitivity of the solution to the choice of propagation approach. This sensitivity arises due the relationship between the crack opening displacements assumed in the VCCT calculation and the actual displacements upon propagation. The four propagation methods are detailed below and shown in Figure 10 and Figure 11. Note for the following discussion that the VCCT calculation is performed at every crack front MPC, "failure" is where the crack growth criteria have been satisfied at an MPC, and "release" of an MPC is a change to the disbonded state 2 .

Propagation Method 1 (PM 1) was the simplest approach, where each failing MPC was released, and the adjacent intact MPCs modified to become crack front MPCs. This was the approach applied in the previous work, and though it was shown to give good predictions compared to results for experimental DCB specimens, a degree of conservatism of the order of $10 \%$ was noted. This was due to the fact that as a result of the crack propagation, the assumption of similarity before and after crack growth could be violated. An example of this is illustrated in Figure 10, for a simplified DCB specimen with large elements. At some point in the analysis failure is detected at only the centre node. This is quite possible, as it is known both theoretically and experimentally that unidirectional DCB specimens develop the highest strain energy rates in the centre of the crack front, due to anti-clastic curvature [20,21]. Applying PM 1, this MPC is released, so that the new crack front is as shown in Figure 10. However, this type of crack growth is different from the self-similar growth assumed in the VCCT calculation. So, the displacements that will result inside the new crack area due to MPC release in this manner are much less than that in the previous increment that was used for the VCCT calculation. This means that the energy released in crack growth would be much less than that calculated using VCCT and would probably fall under the threshold fracture toughness, in which case the crack growth should not have occurred. 
Propagation Method 2 (PM 2) enforced global crack growth, in order to maintain the assumption of self-similar growth. Upon failure at any MPC along the crack front, the entire crack front was grown, that is, all current crack front nodes were released and the adjacent intact MPCs changed to crack front MPCs. This ensured that for the failing MPC, the states of the crack tip before and after crack growth were very similar, which upheld the VCCT assumption. This approach is conservative as it forces crack growth on MPCs that have not failed, which underestimates the fracture toughness of the material. However, for DCB specimens, it is common that the strain energy release rates are nearly constant for the majority of the crack front, with the exception of the edges, at which the strain energy release rates are much less [20]. So, in spite of its conservatism PM 2 was still applicable for DCB specimens and was valuable for comparison with the other methods.

Propagation Method 3 (PM 3) enforced local crack growth, as an approximation in maintaining the assumption of self-similar growth. Any failing MPC was released, and additionally the adjacent crack front nodes that made up the local crack front shape were also released, irrespective of whether these nodes had also failed themselves. This ensured that the local crack front shape was preserved, which assumes that the propagation of only the local crack front shape is enough maintain similarity in the crack opening displacements before and after crack growth. As with PM 2, this approach is conservative as the crack front is grown at locations in which the fracture toughness has not been passed, so that a greater crack area is created than that which the material should be able to withstand.

Propagation Method 4 (PM 4) involved the addition of a separate loop into the fracture mechanics calculation, shown in Figure 11. This additional loop was run between the strain energy release rate calculation and the MPC release, and assessed whether for each failing MPC the energy released in crack growth would correspond to that calculated using VCCT. This was based on an assessment of the shape of the local crack front to be created in the following increment. So, as in the example given for PM 1, if the local crack front created differed from that for self-similar growth, then the values of strain energy release rates were modified to take into account the difference in energy to be released upon crack growth, and the failure criteria were applied again. Further detail on this process is given in the following paragraph. If the failing MPC was deemed to have failed again considering the actual energy to be released, then the MPC was released in the next increment. However, if the energy to be released no longer satisfied the failure criteria, then this MPC was removed from the list of failing MPCs. After the additional loop was completed, if the list of failing MPCs was changed, the loop was restarted, and all remaining failing MPCs rechecked with the same procedure. When the additional loop was completed with no change to the list of failing MPCs, then the subroutine continued, and released all the required MPCs, or no MPCs if all of the failing MPCs had been removed.

The modifications that were made to the strain energy release rate are given in Figure 12, and were the result of considerations for crack growth displacement and area with respect to the difference between the assumptions in the VCCT calculation and the actual crack propagation. For the difference in displacements between the assumed and actual crack propagation, an extensive study of two-step parametric analyses was conducted, similar to CCM steps. As a result of this study, it was found that for any failing MPC, differences in crack opening displacement between two steps of arbitrary global crack growth could be classified according to only the local crack front shape. The different changes to the local crack front shape were then grouped into growth types according to the number of MPCs in 
the local crack front being released between increments. From Figure 12, growth types 1, 2 and 3 involved release of respectively one, two and three of the local crack front MPCs, with the central failing MPC always released. Based on these growth types, the resultant difference in crack growth area from that assumed in the VCCT calculation was determined, using the assumption that the sizes of all surrounding elements were roughly equal. As a result of these considerations, an approximate and conservative modification factor $f_{\text {mod }}$ was determined for each growth type of each crack front shape, as shown in Figure 12. This factor was the value that the strain energy release rates were divided by in order to reflect any difference in released energy as a result of differences in displacement or area caused by a non-assumed growth pattern.

\section{Results and Discussion}

\section{Experimental results}

Experimental tests were performed at DLR on DCB specimens in order to determine the mode I fracture toughness of the unidirectional carbon fibre prepreg material IM7/8552 in accordance with the German standard [22,23], and were presented in Ref. [16]. Table 1 summarises the specimen details, where in the material lay-up "//" is used to denote the location of the delamination in the pre-cracked region. Note that in contrast to the completely unidirectional laminate specified in the standard, a multi-directional laminate was used, as multi-directional laminates find far greater application in aerospace design. A quasi-isotropic lay-up was used that was symmetric about the central $0^{\circ} / 0^{\circ}$ interface, which was expected to minimise any additional anti-clastic curvature, according to the recommendations for testing multi-directional laminates given in Ref [20].

Nine DCB specimens were manufactured with the delamination at the central $0^{\circ} / 0^{\circ}$ interface generated using a Teflon insert. Hinged plates were bonded to the delaminated edges to assist with load introduction, which involved the upper hinge being held whilst the lower hinge was pulled down in displacement control. For each test, the applied load and loading displacement was available from the testing machine as output, which was used to determine the experimental fracture toughness in mode I. The test procedure involved an initial pre-load cycle to generate a "natural" crack front, and then final loading until the total crack length was approximately $100 \mathrm{~mm}$. A typical load-displacement graph is given in Figure 13 for specimen \#7, which also includes the fracture toughness obtained from this test. The results for test \#7 were used as the basis for comparison with numerical analyses, as the experimental fracture toughness of this test was very close to the average fracture toughness of all specimens. For specimen \#7, crack growth initiated at an applied displacement of approximately $1.5 \mathrm{~mm}$, or $106 \mathrm{~N}$, and the loading was stopped at an applied displacement of around $13.2 \mathrm{~mm}$. At the final applied displacement the crack had grown from an initial length of $49.2 \mathrm{~mm}$ to $127.4 \mathrm{~mm}$.

\section{Numerical analysis}

Finite element models were generated with four mesh densities according to the specimen characteristics of Table 1, and were based on those applied in previous work [16]. The mesh densities were characterised according to the element length in the direction of the crack growth, $5 \mathrm{~mm}, 2.5 \mathrm{~mm}, 1.25 \mathrm{~mm}$ and $0.125 \mathrm{~mm}$. For all models, the crack growth region consisted of square elements of the characteristic length joined with the user-defined MPCs. For the $5 \mathrm{~mm}, 2.5 \mathrm{~mm}$ and $1.25 \mathrm{~mm}$ models the crack growth region was $150 \mathrm{~mm}$, 
based on the total crack growth in the experiment. The $0.125 \mathrm{~mm}$ model was created in accordance with Ref. [13], in which element lengths of the order of the ply-thickness are recommended with VCCT. In the previous work the crack growth region for the $0.125 \mathrm{~mm}$ model consisted of only five elements, or $0.625 \mathrm{~mm}$, as this model was only used to investigate crack growth initiation. In this work, the model was extended to contain a crack growth region of $2.5 \mathrm{~mm}$, so that the crack front shape in propagation could be investigated. For the $5 \mathrm{~mm}$ model the entire specimen was modelled with $5 \mathrm{~mm} \times 5 \mathrm{~mm}$ elements, and in the other models a mesh transition scheme to $12.5 \mathrm{~mm} \times 12.5 \mathrm{~mm}$ elements was used, so that the $5 \mathrm{~mm}, 2.5 \mathrm{~mm}, 1.25 \mathrm{~mm}$ and 0.125 models consisted of respectively 500,936 , 3460 and 10,456 four-node bilinear thick-shell elements, as shown in Figure 14. For all models, the intact region outside of the crack growth region was constrained using standard pin-jointed MPCs between the upper and lower sublaminates. The hinge and load application for all models were defined as shown in Figure 15, where the hinges were modelled as single nodes at which the load was applied, and the hinge plates were modelled as rigid regions with pin-joint connections to the hinges. Though the hinge dimensions were based on the hinges used in the experiment, modifications were made in order to match the initial experimental stiffness. This can be considered similar to determining the effective rigid region of the hinge plates, and was necessary so that the hinge modelling did not affect the comparison of crack growth prediction.

The four mesh density models were each run with the four propagation methods, for a total of 16 analysis runs. All models were run on an Intel $1000 \mathrm{MHz}$ Pentium III CPU using the nonlinear solver in Marc, with a full Newton-Raphson procedure applied and the Marc default tolerance of 0.1 on load residuals. For the $0.125 \mathrm{~mm}$ models a relative displacement criterion with tolerance of 0.1 was included as an alternative to the load residuals, as it was found that large numbers of MPCs released between increments affected the energy balance of the structure and lead to convergence problems. The $5 \mathrm{~mm}, 2.5 \mathrm{~mm}$ and $1.25 \mathrm{~mm}$ models were each run with $13 \mathrm{~mm}$ applied displacement load, while the $0.125 \mathrm{~mm}$ models were only run to an applied displacement of $1.5 \mathrm{~mm}$ with PMs 1,2 and 3 and $1.8 \mathrm{~mm}$ with PM 4. Analysis results are presented below, where Figure 16 and Figure 17 are typical comparative curves for applied load versus displacement, Figure 18 is a comparison of the strain energy release rate before any crack growth, and Figure 19 illustrates the effect of both mesh density and propagation method on crack progression. Table 2 is a summary of all analysis results, where $P_{\max }$ is the maximum load reached, $a_{\max }$ is the total crack length at $13 \mathrm{~mm}$ displacement, and $P_{\text {init }}$ is the load at initiation, which is given for $0.125 \mathrm{~mm}$ models. Table 3 is a summary of all analysis times, where $t$ is the total analysis time, inc is the total number of increments, and $t_{i n c}$ is the average time per increment.

All models displayed similar behaviour regardless of propagation method, which involved an initially linear region leading up to the initiation of crack growth, and crack growth characterised by reductions in the load-carrying behaviour corresponding to advances in the crack front. For all $5 \mathrm{~mm}, 2.5 \mathrm{~mm}$ and $1.25 \mathrm{~mm}$ models, the crack advanced as a straight crack, and alternated between a stationary full width straight crack and a jagged crack front in crack growth. This behaviour was reflected in the "saw-tooth" appearance of all loaddisplacement curves that was more pronounced for the $5 \mathrm{~mm}$ model, and in general the straight and jagged crack fronts corresponded to increasing and decreasing loaddisplacement behaviour respectively. The drop in load upon crack growth corresponded to the distance of crack advance and the number of MPCs released, and the use of smaller elements resulted in a smoother load-displacement curve. The sequence of failing MPCs along the crack front was usually identical between growth steps for each different mesh 
density and propagation method, and this sequence was largely symmetrical for all models. For the $0.125 \mathrm{~mm}$ model, PMs 1,3 and 4 all showed crack growth from the initially straight crack front into a thumbnail shape, and crack propagation then continued in this thumbnail shape. Though no information on the crack front shape was available from the tests performed, the thumbnail crack front shape is a phenomenon for DCB specimens that is well known both theoretically and experimentally, and is due to the anti-clastic curvature of the structure [20,21]. For the $0.125 \mathrm{~mm}$ model with PM 2, straight crack front propagation was observed as the implementation of global crack front growth meant that the initial straight crack front was always enforced.

PM 1 predicted the load at crack growth initiation within $13 \%$, captured the load-carrying behaviour in crack growth very well, and gave excellent comparison with the final crack length. As no change to the initiation criteria was made in PMs 2 and 3, these methods gave identical predictions for crack growth initiation. PM 2 gave almost identical behaviour to PM 1 for the entire loading, though with run times that were slightly less than PM 1 and the shortest of all propagation methods. The identical behaviour between PMs 1 and 2 is due to the fact that the crack front shape and location remained identical for the times in which the crack was stationary, in spite of the two approaches giving a different sequence of failing MPCs. In contrast, PM 3 gave results that significantly underestimated the loaddisplacement behaviour, with a slight increase in analysis time. The underestimation of PM 3 was surprising as it was expected to be less conservative than PM 2 given that it involved less MPCs being forced to fail. However, from inspection of the crack front progression, it was seen that in contrast to PMs 1 and 2 that essentially propagated a straight crack front, PM 3 resulted in the propagation of a jagged crack front shape consisting of a series of corners and edges. This configuration of crack front had less structural stiffness than the straight crack front, and critically the jagged edges were more likely to initiate further crack growth, which only worsened the underestimation problem. PM 3, unlike PM 2, enforced crack growth in a manner that was not representative or realistic for DCB specimens, and so an incorrect crack front was generated and propagated.

PM 4, in which the strain energy release rates were adjusted based on the new crack front, gave excellent comparisons for all aspects of the structural response. In comparison with the experimental results, the maximum applied load was within $5 \%$ and the total crack length was within $9 \%$ for all mesh density models, though the predictions of total crack length were slightly less accurate than for PM 1 and PM 2. The modification process in effect added a delay to the onset of crack growth, which appeared to alleviate the conservatism shown in PMs 1, 2 and 3. Figure 20 shows the initiation of crack growth with PM 1 and PM 4, which highlights the improved prediction of the actual strain energy released upon crack growth.

In general, the trends for mesh density and analysis time were identical to those observed previously from only the PM 1. For all models, the selection of the increment size was critical in order to ensure that the load was not increased disproportionately to the crack growth. That is, the increment size had to be small enough so that any crack growth required could take place without further increase in load. For this reason, for the $5 \mathrm{~mm}, 2.5$ $\mathrm{mm}, 1.25 \mathrm{~mm}$ and $0.125 \mathrm{~mm}$ models increments sizes of respectively $0.1 \mathrm{~mm}, 0.05 \mathrm{~mm}$, $0.02 \mathrm{~mm}$ and $0.001 \mathrm{~mm}$ were applied. The result of this was that the increase in mesh density doubly penalised the total analysis time due to the increase in both computational expense and required number of increments. This can be seen in Table 3 , where the $t_{\text {inc }}$ value is an attempt to give a more realistic appreciation of the computational expense for 
each model, and though this value does not account for iterations, the number of iterations was fairly constant between increments. Similarly, the effect of mesh density on the specimen behaviour was similar to that previously reported, in that the mesh density did not significantly affect the overall structural response and crack propagation behaviour. There were slight differences in the exact crack propagation shapes and strain energy release rate distributions, most noticeably for the $5 \mathrm{~mm}$ model, though from the load-displacement results these did not affect the global specimen response of any model.

\section{Discussion}

Propagation Method 4 gave the closest comparison to the experimental results, and appears to offer an accurate and certainly less conservative approach for handling crack growth propagation using VCCT. However, the relationships between local crack front shape and energy released in crack growth determined for this specimen may not be applicable to all other types of structures and all other types of crack growth. In particular it remains to be investigated in future work whether the observations made here on the differences between VCCT and the actual energy released in propagation are suitable for mode II and mixedmode displacements. Moreover, the comparison of the various propagation methods may be specific to some aspect of this particular example such as the specimen configuration, boundary conditions or material properties, and further study is required before a decision can be made between PMs 1 and 4. This is because in spite of its conservatism, the simple fail-release approach of PM 1 still provided a very good level of accuracy for this example, and required less computational effort than PM 4, which may have important implications for larger and more complex models. The results for PM 2 and PM 3 both illustrated the importance of implementing a crack propagation approach that is realistic for the structure being investigated. Whilst the global crack growth approach of PM 2 may not be realistic in many cases, it may still provide a useful comparison in some instances especially for models in which the analysis time is critical.

More generally, the results confirmed the observation made in the previous work that the VCCT approach can remain accurate for large mesh sizes, and can be used to make predictions on the load-carrying capacity and structural response. This is a necessary requirement for a degradation model in order to be applicable to large skin-stiffened structures. Also, the results indicate that the approach is suitable for obtaining detailed information on the crack initiation and crack shape, though this does require significant computational effort. It must be noted that many researchers have found VCCT to give mesh-dependent results, especially for the so-called "bi-material" interface between two dissimilar sublaminates [13]. It remains to be seen whether the VCCT approach developed will encounter difficulties in the analysis of a bi-material interface, which would be problematic as these types of interfaces are very common in stiffened structure designs. As a result of this, mesh density studies and a comparison with a ply-thickness element length model may be required for each different structural configuration investigated, in the manner demonstrated in this paper.

Future development of the degradation model will focus on the goal of application to large fuselage-representative structures. Gap elements or a contact definition will be implemented to prevent the penetration of shell layers in the disbonded region, though this was not required here for the DCB specimens. Also, the initiation of delaminations and disbonds from an intact structure will be investigated, and this will be incorporated into the current capacity for modelling disbond growth. A separate approach will be developed to 
represent the intralaminar damage mechanisms such as fibre fracture, matrix cracking and fibre-matrix shear failure, and this will be applied in parallel with the interlaminar disbond damage. The development of the various degradation models will also benefit from the large amount of testing carried out as part of the COCOMAT project, which includes other fracture mechanics coupon tests such as End Notched Flexure and Mixed Mode Bending, single-stiffener flat panels in compression both with and without pre-existing disbond regions, and large multi-bay curved stiffened panels both with and without various damage types. The application of the degradation model to these experimental results will be critical for the development, validation and demonstration of the proposed degradation modelling approach.

\section{Conclusion}

A method to analyse the propagation of delaminations in composite structures has been developed. The model was implemented for nonlinear finite element analysis using two user subroutines in Marc. In the developed approach, user-defined MPCs were applied to control the connection of two shell element layers. At the end of every increment, fracture mechanics calculations were performed using VCCT and any failing MPCs were released for the next increment. As previous work had demonstrated a slight conservatism in a simple fail-release approach, three new methods for the release of failing MPCs were proposed. Using this approach, the disbonded area could be grown during an analysis and the structural degradation due to disbonding represented.

Numerical predictions using the degradation model with the four propagation methods were compared to experimental results for double cantilever beam specimens. In general, close comparison was observed for all aspects of structural behaviour, which included the loadcarrying capacity, structural deformation and crack propagation. In terms of the propagation methods, the closest comparison was achieved with an approach that modified the strain energy release rate values based on the crack front created in the next increment. This approach was shown to give more accurate results than a simple fail-release approach, as it gave a closer relationship between the assumed and actual energy released in crack growth. Importantly, it was also shown that the use of VCCT with relatively large elements gave almost identical results to even a ply-thickness element length model, and that the use of smaller elements was doubly disadvantageous for computation time as it also required the use of small increment sizes. Recommendations were made for the future development of the degradation model, with reference to the application of the method to other specimen types and stiffened structures representative of composite fuselage designs.

\section{Acknowledgments}

The authors kindly acknowledge the financial support of: the European Commission, Priority Aeronautics and Space, Contract AST3-CT-2003-502723; the Australian Postgraduate Awards Scheme; the German Academic Exchange Service, the Italian Ministry of Foreign Affairs, and; the Australian Government under the "Innovation Access Programme - International Science and Technology". The authors would also like to acknowledge the generous assistance of Dr Michael Giess of MSC.Software Australia, and Prof. Murray Scott of the CRC-ACS for support within the COCOMAT project. 


\section{References}

1. R. Degenhardt, R. Rolfes, R. Zimmerman and K. Rohwer, "COCOMAT - Improved MATerial Exploitation at Safe Design of COmposite Airframe Structures by Accurate Simulation of COllapse," Comp. Struct., 73, 178-178 (2006).

2. COCOMAT Home Page, www.cocomat.de, (2006).

3. T. K. O'Brien, "Characterization of delamination onset and growth in a composite laminate," in: Damage in Composite Materials, ASTM STP 775 (1982), pp. 140-167.

4. T. K. O'Brien, "Interlaminar fracture toughness: The long and winding road to standardization," Comp. B, 29, 57-62 (1998).

5. E. F. Rybicki and M. F. Kanninen, "A finite element calculation of stress intensity factors by a modified crack closure integral,” Eng. Fract. Mech., 9, 931-938 (1977).

6. R. Krüger, M. König and T. Schneider, "Computation of local energy release rates along straight and curved delamination fronts of unidirectionally laminated DCB- and ENF- specimens," in: Proceedings of the $34^{\text {th }}$ AIAA/ASME/ASCE/AHS/ASC SSDM Conference, La Jolla, CA: AIAA Washington (1993), pp. 1332-1342.

7. J. Li, S. M. Lee, E. W. Lee and T. K. O'Brien, "Evaluation of the edge crack torsion ECT Test for mode III interlaminar fracture toughness of laminated composites," J. Comp. Tech. Res., 19, 174-183 (1997).

8. M. M. A. Wahab, "On the use of fracture mechanics in designing a single lap adhesive joint," J. Adhes. Sci. Technol., 19, 851-865 (2000).

9. M. Qin and Y. Dzenis, "Nonlinear numerical and experimental analysis of single lap adhesive composite joints with delaminated adherends," in: Proceedings of the Thirteenth International Conference on Composite Materials (ICCM13), Y. Zhang, Ed., Beijing (2001).

10. J. T. Wang and I. S. Raju, "Strain energy release rate formulae for skin-stiffener debond modeled with plate elements," Eng. Fract. Mech., 54, 211-228 (1996).

11. J. Li, T. K. O'Brien and C. Q. Rousseau, "Test and analysis of composite hat stringer pull-off test specimens,” J. Amer. Heli. Soc., 350-357 (1997).

12. W. S. Johnson, L. M. Butkus and R. V. Valentin, Applications of Fracture Mechanics to the Durability of Bonded Composite Joints, U.S. Department of Transportation, Federal Aviation Administration DOT/FAA/AR-97/56, (1998).

13. R. Krueger, The Virtual Crack Closure Technique: History, Approach and Applications, NASA/CR-2002-211628, ICASE Virginia, USA (2002).

14. P. P. Camanho and C. G. Dávila, Mixed-mode Decohesion Finite Elements for the Simulation of Delamination in Composite Materials, NASA/TM-2002-211737, NASA Langley Research Center, Virginia, USA (2002).

15. Y. Mi, M. A. Crisfield and G. A. O. Davies, "Progressive delamination using interface elements," J. Comp. Mat., 32, No. 14, 1246-1272 (1998).

16. A. Orifici, R. Thomson, R. Degenhardt and J. Bayandor, "Development of a degradation model for the collapse analysis of composite aerospace structures," in: Proceedings of the Third European Conference on Computational Mechanics: Solids, Structures and Coupled Problems in Engineering, C. A. Mota Soares et al. Eds, Lisbon, Portugal, 5-9 June (2006). 
17. J. W. H. Yap, R. S. Thomson, M. L. Scott and D. Hachenberg, "Influence of postbuckling behaviour of composite stiffened panels on the damage criticality," Comp. Struct., 66, 197-206 (2004).

18. MSC.Marc and MSC.Mentat User Manuals Version 2005, MSC.Software Corporation, Santa Ana, CA, (2004).

19. G. R. Irwin, "Fracture I," in: Handbook der Physik, Flügge, Ed., (1958), pp. 558-590.

20. B. D. Davidson, "An analytical investigation of delamination front curvature in double cantilever beam specimens," J. Compos. Mater., 24, 1124-1137 (1990).

21. A. J. Brunner, "Experimental aspects of Mode I and Mode II fracture toughness testing of fibre-reinforced polymer-matrix composites," Comput. Meth. Appl. Mech. Engrg., 185, 161-172 (2000).

22. Kling A., Degenhardt R., Characterization of material properties - Results of the EU project COCOMAT, Internal DLR Report, IB 131-2006/18, April 2006.

23. Determination of Interlaminar Fracture Toughness Energy - Mode I - GIC. European Normative Standard DIN EN 6033, Deutsches Institut für Normung, e. V., 1996. 


\section{Figure Captions}

Figure 1: Crack opening modes (a) I. Opening (b) II. Sliding (c) III. Scissoring.

Figure 2: DCB modelling with user-defined MPCs.

Figure 3: Laminate definition with dummy layers shown.

Figure 4: Error in interlaminar shear stress distribution due to zero-stiffness layers.

Figure 5: Nonlinear analysis flow with user subroutines for degradation modelling.

Figure 6: Crack closure method (a) Step 1: Crack closed (b) Step 2: Crack extended.

Figure 7: VCCT model with arbitrary rectangular shell elements.

Figure 8: Determining the local crack front coordinate system for an arbitrary crack front, adapted from [13].

Figure 9: Crack front pattern, VCCT MPCs and crack growth area for each crack growth type.

Figure 10: Analysis flow and example growth for Propagation Methods 1, 2 and 3.

Figure 11: Analysis flow and several possible example growths for Propagation Method 4.

Figure 12: Modification values for Propagation Method 4, for each crack front type and growth type.

Figure 13: Applied load versus displacement for DCB Test \#7, with resultant fracture toughness value given.

Figure 14: Detail of the mesh transition scheme, $2.5 \mathrm{~mm}$ and $0.125 \mathrm{~mm}$ models shown.

Figure 15: DCB modelling overview, showing hinge modelling and boundary conditions. 
Figure 16: Applied load versus displacement, Experimental Test and $2.5 \mathrm{~mm}$ model with PMs 1-4.

Figure 17: Applied load versus displacement, Experimental Test and PM 1 with $5 \mathrm{~mm}, 2.5$ $\mathrm{mm}, 1.25 \mathrm{~mm}$ and $0.125 \mathrm{~mm}$ models.

Figure 18: Strain energy release rate at $1.3 \mathrm{~mm}$ applied displacement (before crack growth), all FE models.

Figure 19: Crack growth progression with applied displacement for: PM 1 with all models, and; the $2.5 \mathrm{~mm}$ model with all propagation methods.

Figure 20: Crack growth initiation for PMs 1 and 4, showing the difference between assumed and actual strain energy release rates for both methods. 
Table 1: Geometry and material specifications for DCB experimental tests.

\begin{tabular}{ll}
\hline Length & $250 \mathrm{~mm}$ \\
Width & $25 \mathrm{~mm}$ \\
Teflon insert & $25 \mathrm{~mm} \times 25 \mathrm{~mm} \times 0.02 \mathrm{~mm}$ \\
Crack extension from pre-load $^{*}$ & $25 \mathrm{~mm}$ \\
Total pre-crack length $^{*}$ & $50 \mathrm{~mm}$ \\
Layup & {$\left[(0,90,+45,-45)_{2 \mathrm{~S}} / /(0,90,+45,-45)_{2 \mathrm{~S}}\right]$} \\
Ply thickness & $0.152 \mathrm{~mm}$ \\
Total thickness & $4.864 \mathrm{~mm}$ \\
\hline
\end{tabular}

"Approximate value taken from DCB Test \#7

Table 2: FE analysis summary, for all FE models and all propagation methods.

\begin{tabular}{|c|c|c|c|c|c|c|c|c|c|c|}
\hline \multirow{2}{*}{ PM } & \multicolumn{2}{|c|}{$\begin{array}{c}5 \mathrm{~mm} \\
\text { MPCs: } 132\end{array}$} & \multicolumn{2}{|c|}{$\begin{array}{c}2.5 \mathrm{~mm} \\
\text { MPCs: } 462\end{array}$} & \multicolumn{2}{|c|}{$\begin{array}{c}1.25 \mathrm{~mm} \\
\text { MPCs: } 1722\end{array}$} & \multicolumn{2}{|c|}{$\begin{array}{c}0.125 \mathrm{~mm} \\
\text { MPCs: } 4422\end{array}$} & \multicolumn{2}{|c|}{$\begin{array}{c}\text { DCB } \\
\text { Test \# } 7\end{array}$} \\
\hline & $\begin{array}{l}\mathrm{P}_{\max } \\
{[\mathrm{N}]}\end{array}$ & $\begin{array}{r}\mathrm{a}_{\max } \\
{[\mathrm{mm}]}\end{array}$ & $\begin{array}{l}\mathrm{P}_{\max } \\
{[\mathrm{N}]}\end{array}$ & $\begin{array}{c}\mathrm{a}_{\max } \\
{[\mathrm{mm}]}\end{array}$ & $\begin{array}{l}\mathrm{P}_{\max } \\
{[\mathrm{N}]}\end{array}$ & $\begin{array}{c}\mathrm{a}_{\max } \\
{[\mathrm{mm}]}\end{array}$ & $\begin{array}{l}\mathrm{P}_{\text {init }} \\
{[\mathrm{N}]}\end{array}$ & $\begin{array}{l}\mathrm{a}_{\max }{ }^{*} \\
{[\mathrm{~mm}]}\end{array}$ & $\begin{array}{l}\mathrm{P}_{\max } \\
{[\mathrm{N}]}\end{array}$ & $\begin{array}{r}\mathrm{a}_{\max } \\
{[\mathrm{mm}]}\end{array}$ \\
\hline 1 & 92.4 & 130 & 93.2 & 127.5 & 91.4 & 128.8 & 89.2 & - & \multirow{4}{*}{108} & \multirow{4}{*}{127.4} \\
\hline 2 & 92.4 & 130 & 93.2 & 127.5 & 90.7 & 127.5 & 89.2 & - & & \\
\hline 3 & 92.4 & $>150$ & 93.2 & $>150$ & 90.7 & $>150$ & 89.2 & - & & \\
\hline 4 & 112.1 & 120 & 113.0 & 117.5 & 111.9 & 116.3 & 109.2 & - & & \\
\hline
\end{tabular}

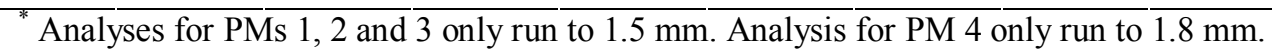

Table 3: FE analysis time summary, for all FE models and all propagation methods.

\begin{tabular}{c|c|c|c|c|c|c|c|c|c|c|c|c}
\hline \multirow{3}{*}{ PM } & \multicolumn{3}{|c|}{$5 \mathrm{~mm}$} & \multicolumn{3}{c|}{$2.5 \mathrm{~mm}$} & \multicolumn{3}{c|}{$1.25 \mathrm{~mm}$} & \multicolumn{3}{c}{$0.125 \mathrm{~mm}$} \\
\cline { 2 - 12 } & $\begin{array}{c}\mathrm{t} \\
{[\mathrm{hr}]}\end{array}$ & inc & $\begin{array}{c}\mathrm{t}_{\text {inc }} \\
{[\mathrm{s}]}\end{array}$ & $\begin{array}{c}\mathrm{t} \\
{[\mathrm{hr}]}\end{array}$ & inc & $\begin{array}{c}\mathrm{t}_{\text {inc }} \\
{[\mathrm{s}]}\end{array}$ & $\begin{array}{c}\mathrm{t} \\
{[\mathrm{hr}]}\end{array}$ & inc & $\begin{array}{c}\mathrm{t}_{\text {inc }} \\
{[\mathrm{s}]}\end{array}$ & $\begin{array}{c}\mathrm{t}^{*} \\
{[\mathrm{hr}]}\end{array}$ & $\begin{array}{c}\text { inc } \\
\mathrm{t}_{\text {inc }} \\
{[\mathrm{s}]}\end{array}$ \\
\hline 1 & 0.57 & 121 & 16.9 & 1.69 & 235 & 25.9 & 16.0 & 586 & 98.4 & 11.7 & 151 & 279.2 \\
2 & 0.52 & 121 & 15.4 & 1.15 & 235 & 17.7 & 11.7 & 586 & 71.7 & 8.16 & 151 & 194.6 \\
3 & 0.59 & 121 & 17.5 & 1.79 & 235 & 13.8 & 13.8 & 586 & 84.7 & 9.69 & 151 & 231.0 \\
4 & 0.51 & 121 & 15.1 & 2.00 & 235 & 18.8 & 18.8 & 586 & 115.5 & 9.57 & 151 & 228.1 \\
\hline
\end{tabular}




\section{Figures}

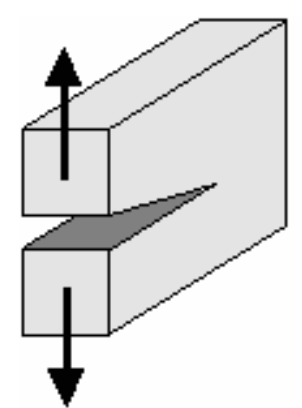

(a)

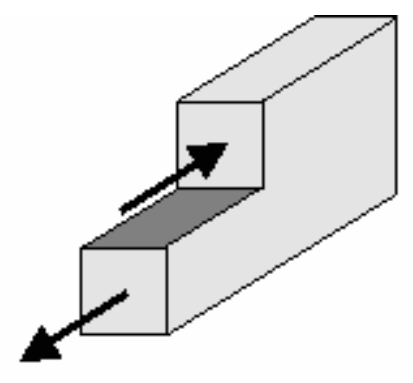

(b)

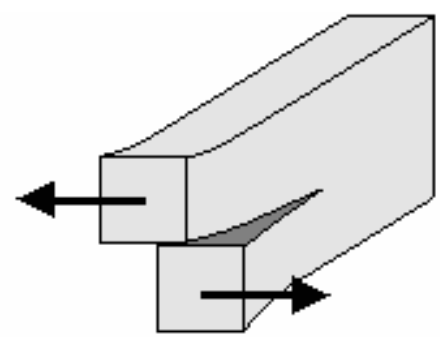

(c)

Figure 1: Crack opening modes (a) I. Opening (b) II. Sliding (c) III. Scissoring.

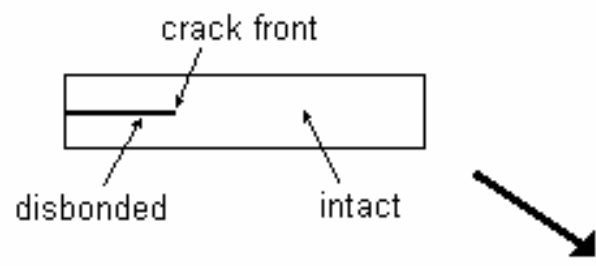

User-defined MPCs

- state 0: intact

- state 1: intact, crack front

o state 2: disbonded

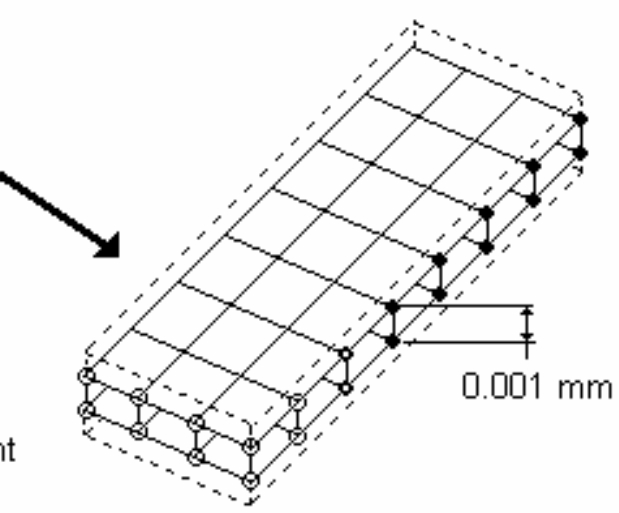

Figure 2: DCB modelling with user-defined MPCs.

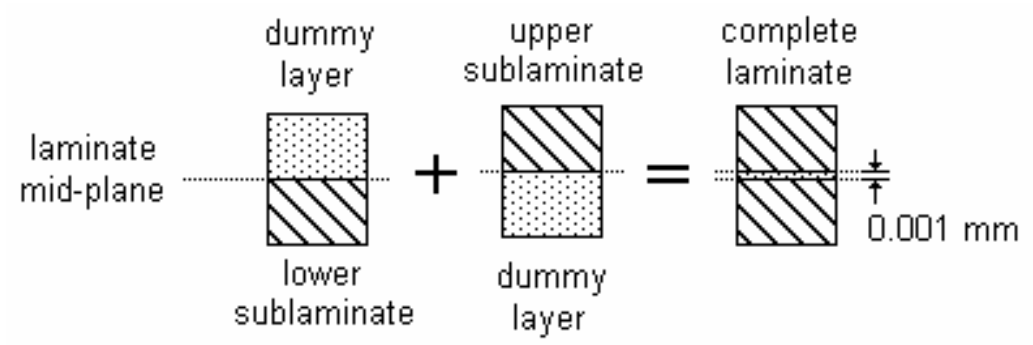

Figure 3: Laminate definition with dummy layers shown.

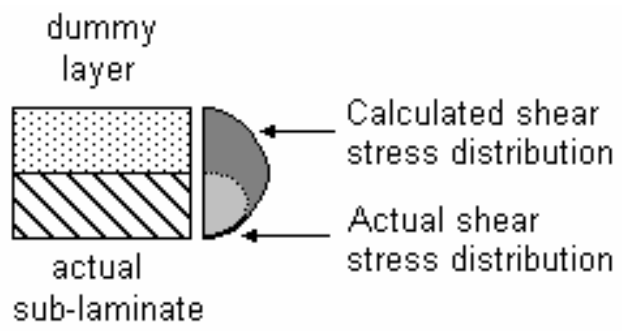

Figure 4: Error in interlaminar shear stress distribution due to zero-stiffness layers. 


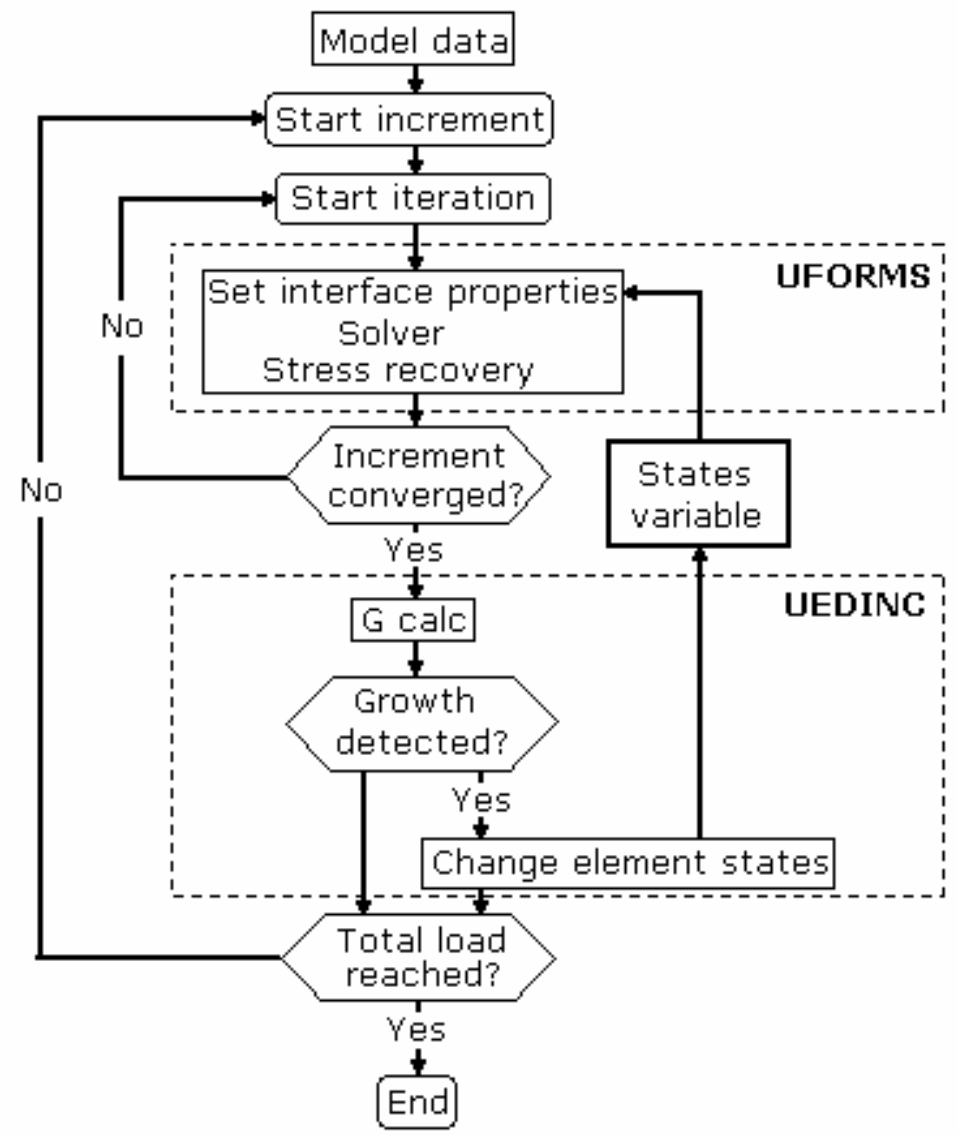

Figure 5: Nonlinear analysis flow with user subroutines for degradation modelling.

Step 1: Crack held

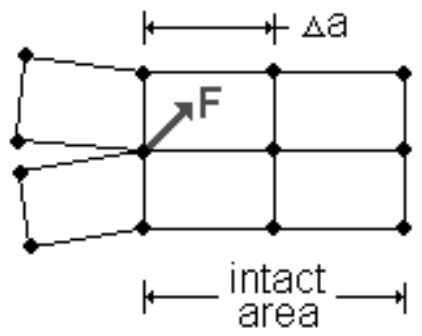

(a)
Step 2: Crack released

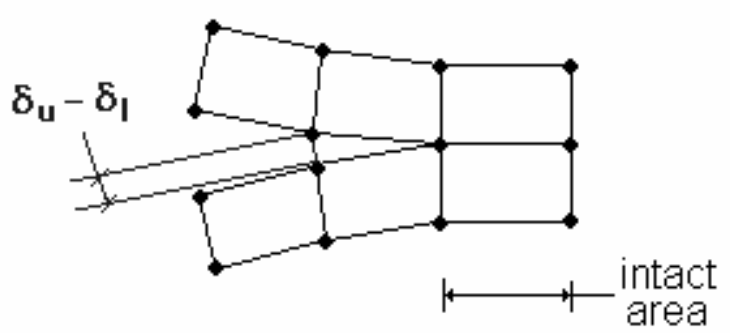

(b)

Figure 6: Crack closure method (a) Step 1: Crack closed (b) Step 2: Crack extended.

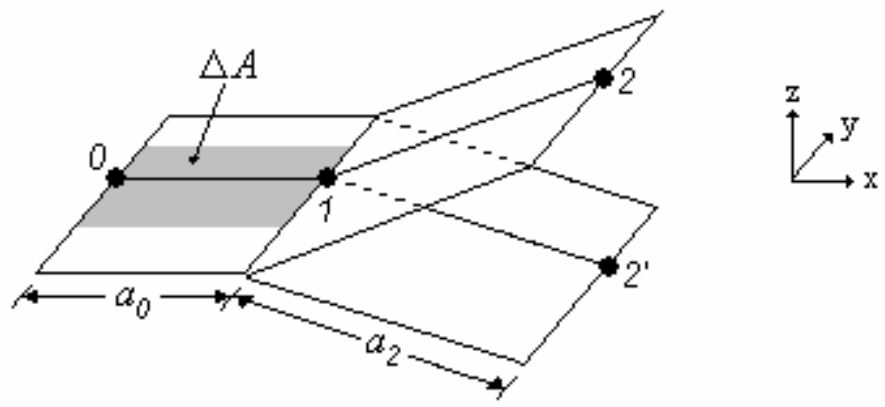

Figure 7: VCCT model with arbitrary rectangular shell elements. 

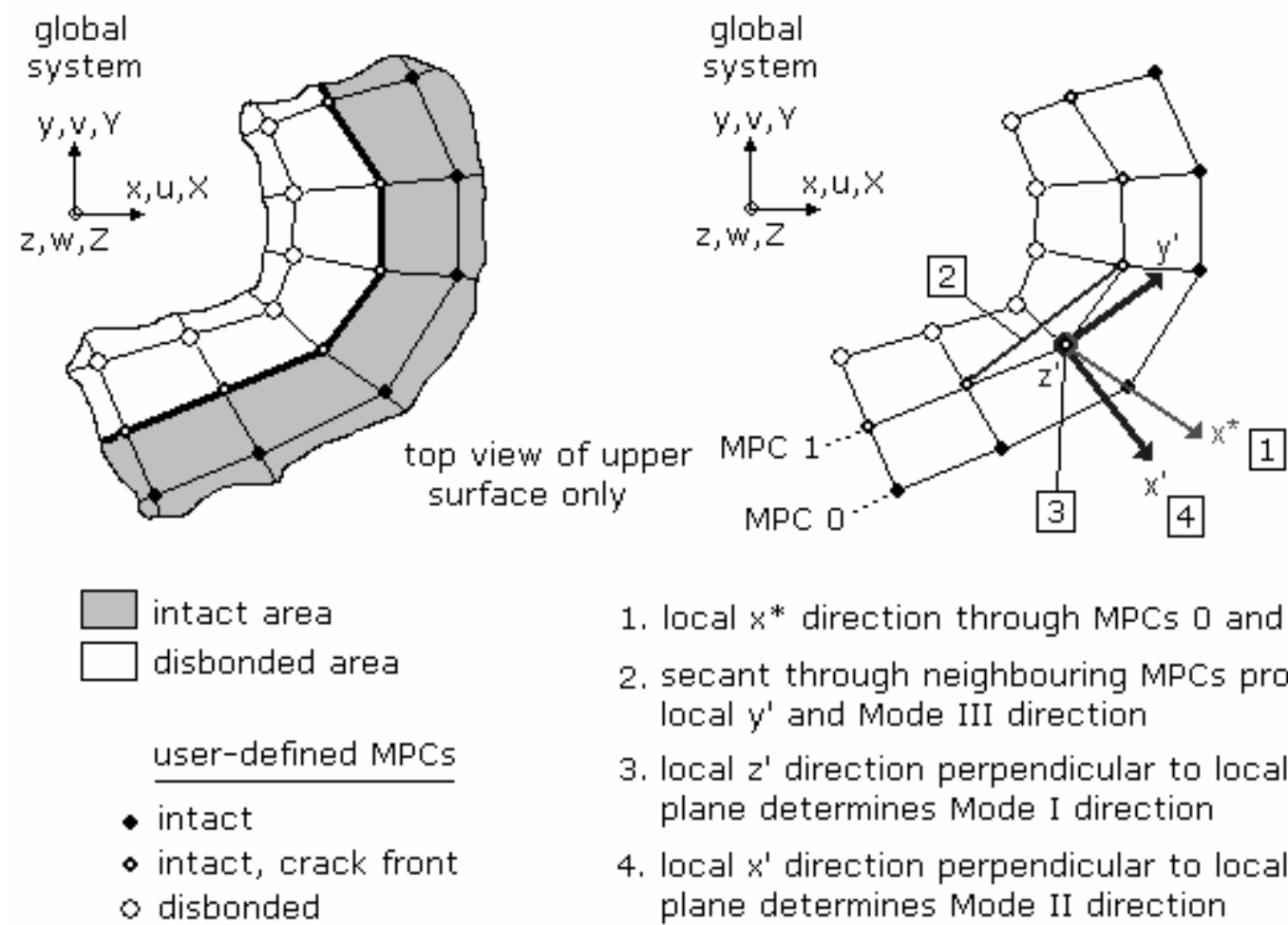

1. local $x^{*}$ direction through MPCs 0 and 1

2. secant through neighbouring MPCs provides local $y^{\prime}$ and Mode III direction

3. local $z^{\prime}$ direction perpendicular to local $x^{*}-y^{\prime}$ plane determines Mode I direction

4. local $x^{\prime}$ direction perpendicular to local $y^{\prime}-z^{\prime}$ plane determines Mode II direction

Figure 8: Determining the local crack front coordinate system for an arbitrary crack front, adapted from [13]. 


\begin{tabular}{|c|c|c|c|c|}
\hline Crack Type & Side MPCs & Pattern & VCCT MPCs & Area \\
\hline 1 & 1 intact & & & \\
\hline 2 & $\begin{array}{l}1 \text { intact } \\
2 \text { disbond }\end{array}$ & & & \\
\hline 3 & $\begin{array}{l}1 \text { intact } \\
3 \text { disbond }\end{array}$ & & & \\
\hline 4 & $\begin{array}{l}2 \text { intact } \\
1 \text { disbond }\end{array}$ & & & \\
\hline 5 & 2 intact & & & \\
\hline 6 & $\begin{array}{l}3 \text { intact } \\
1 \text { disbond }\end{array}$ & & & \\
\hline & 1 intact & & & \\
\hline 7 & $\begin{array}{l}1 \text { disbond } \\
\text { (on edge) }\end{array}$ & & & \\
\hline 8 & $\begin{array}{l}1 \text { intact } \\
1 \text { disbond } \\
\text { (on edge) }\end{array}$ & & & \\
\hline 9 & $\begin{array}{c}1 \text { intact } \\
2 \text { disbond } \\
\text { (on edge) }\end{array}$ & & & \\
\hline $10^{*}$ & $\begin{array}{c}0 \text { intact } \\
2 \text { disbond }\end{array}$ & & & \\
\hline 11 & $\begin{array}{l}2 \text { intact } \\
0 \text { disbond }\end{array}$ & & & \\
\hline
\end{tabular}

* Non self-similar crack growth assumption

Side MPCs: MPCs directly adjacent to central crack front MPC (-)

Pattern: $\quad$ intact $\square$ disbonded $\quad$ crack front

VCCT MPCs: $\quad \times$ new location $\quad$ displacements $\quad$ local crack front

Area: $\quad \nabla$ crack area - old crack front - new crack front

Figure 9: Crack front pattern, VCCT MPCs and crack growth area for each crack growth type. 


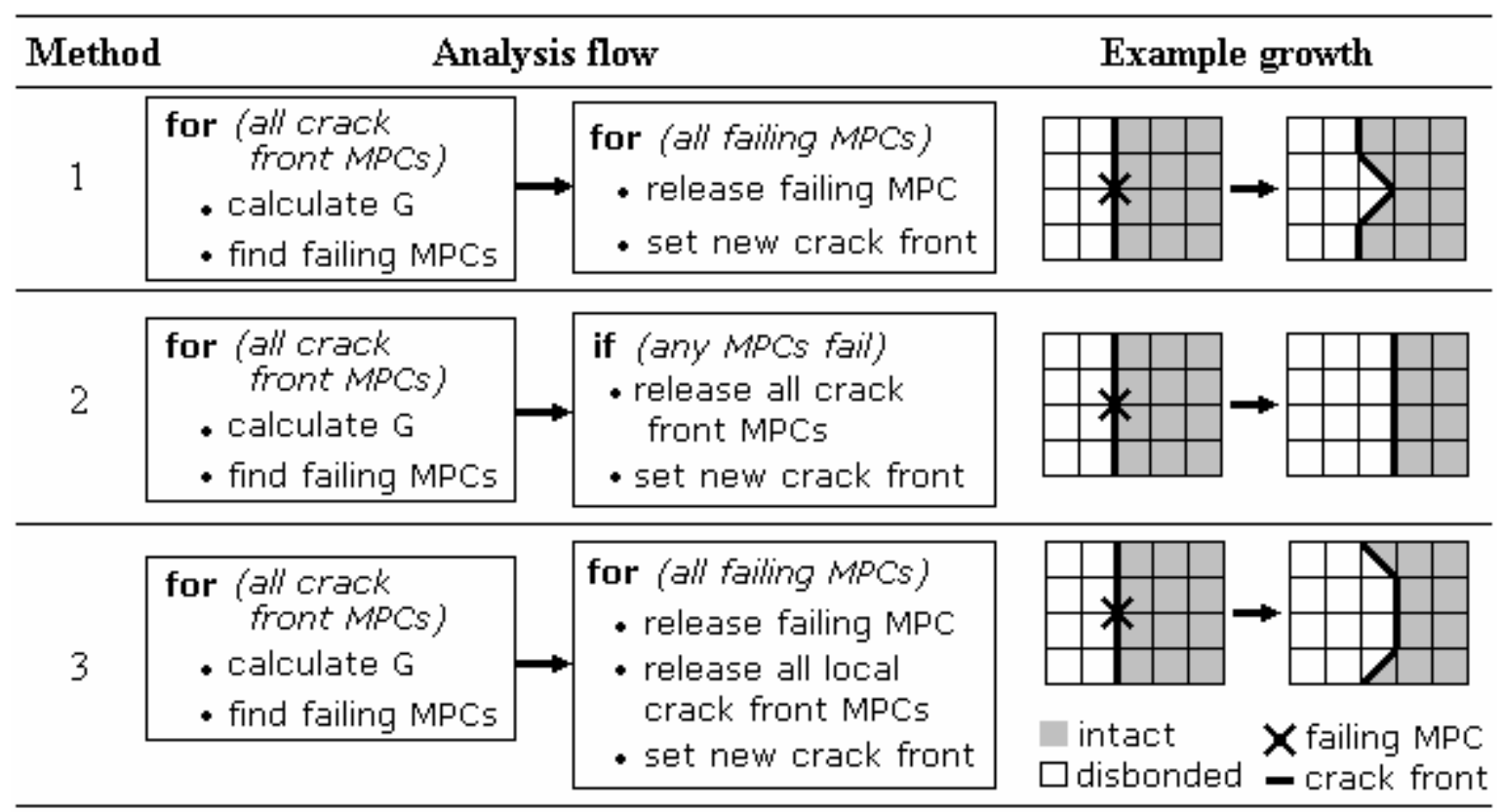

Figure 10: Analysis flow and example growth for Propagation Methods 1, 2 and 3.

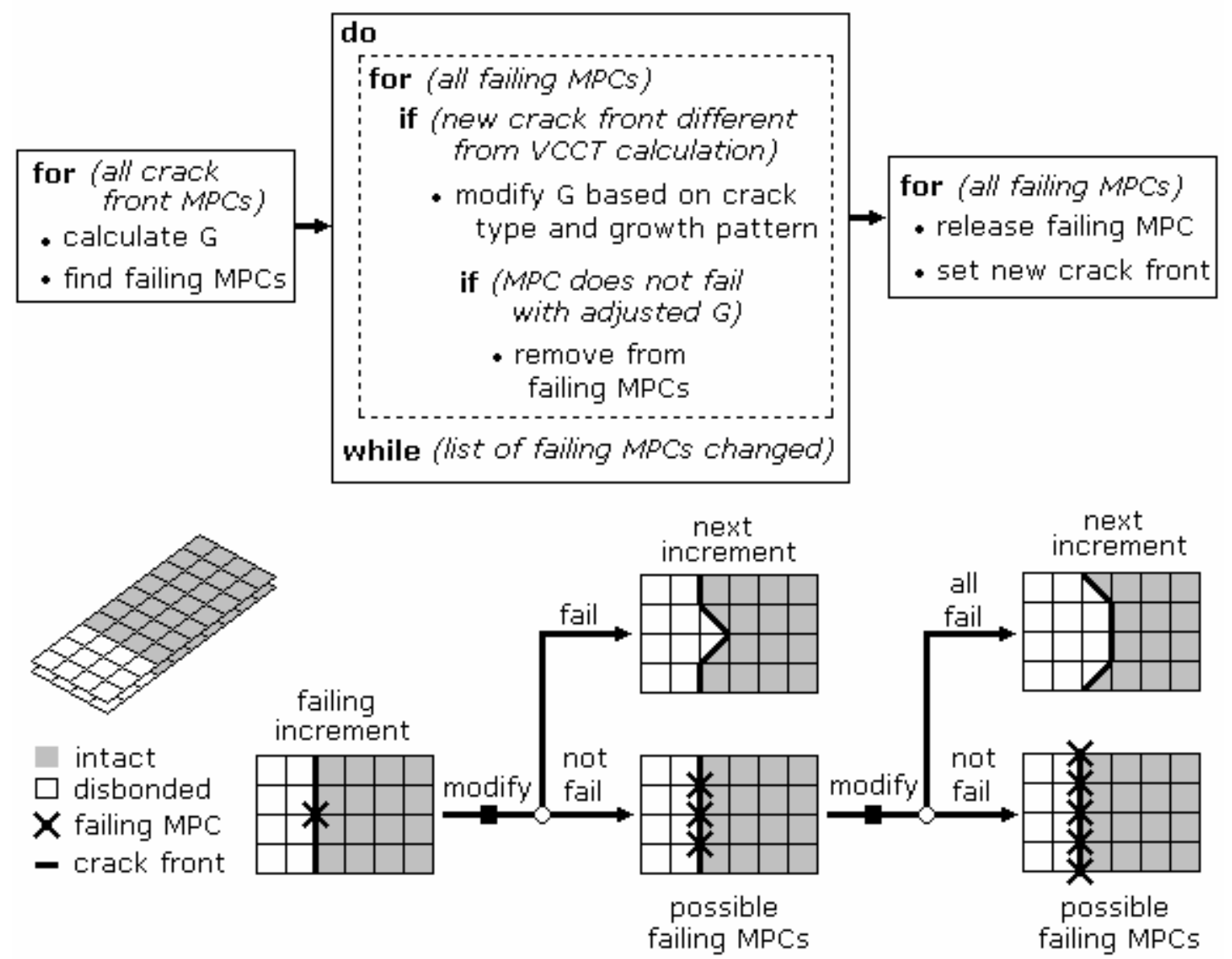

Figure 11: Analysis flow and several possible example growths for Propagation Method 4. 


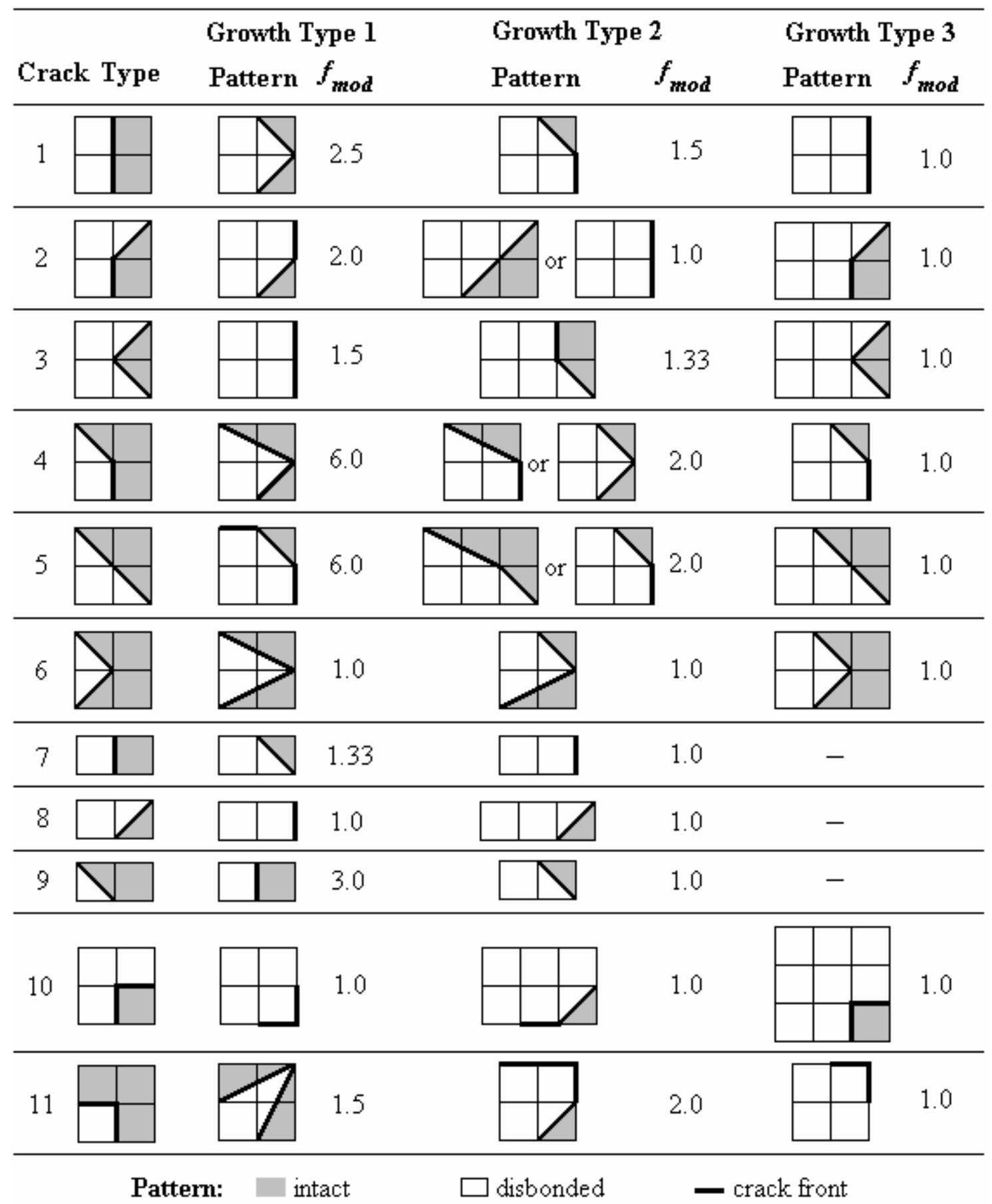

Figure 12: Modification values for Propagation Method 4, for each crack front type and growth type. 


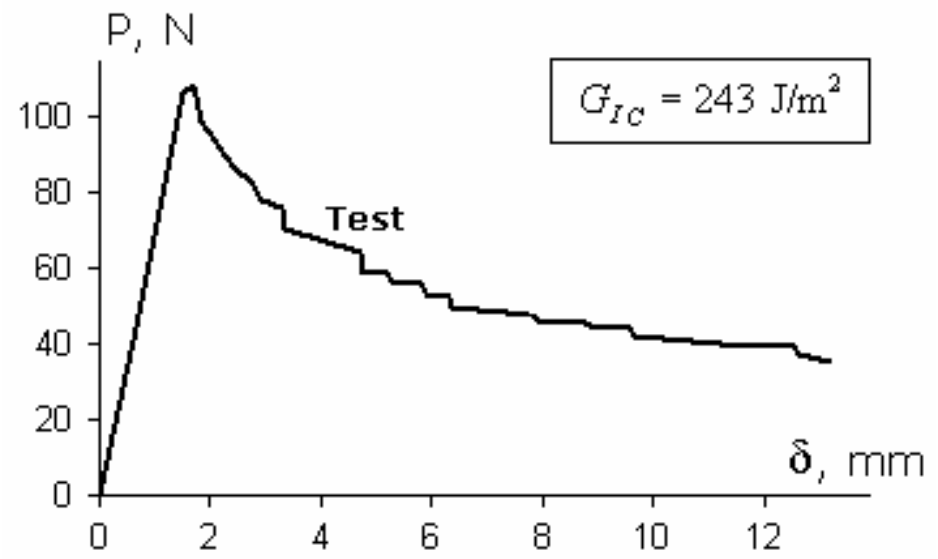

Figure 13: Applied load versus displacement for DCB Test \#7, with resultant fracture toughness value given.

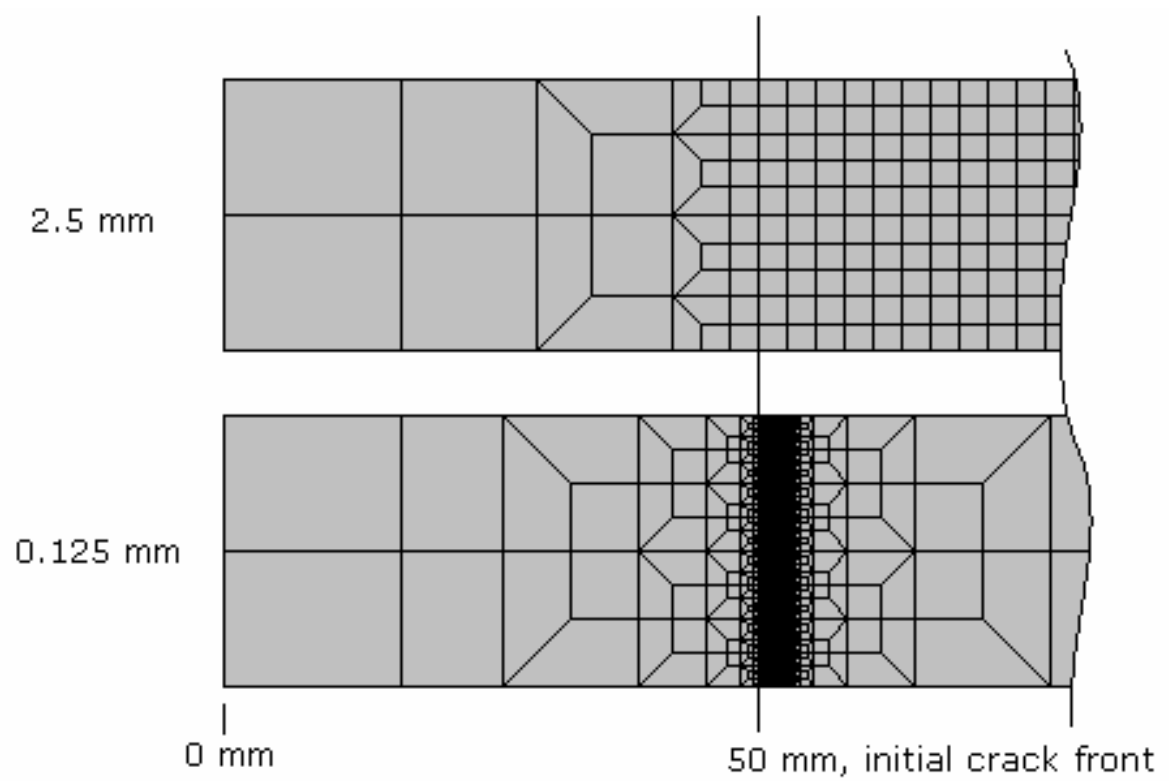

Figure 14: Detail of the mesh transition scheme, $2.5 \mathrm{~mm}$ and $0.125 \mathrm{~mm}$ models shown. 

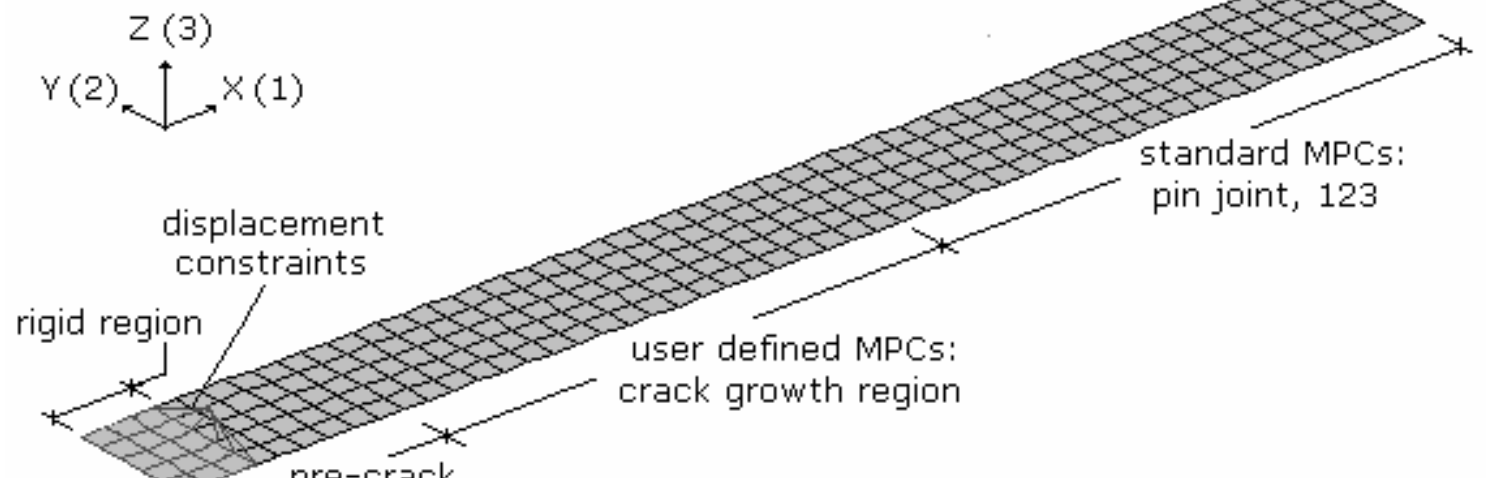

pre-crack

region

\section{upper grip}

BC 12346



lower grip: applied load

$z(3)$

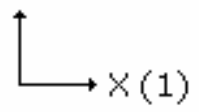

$x(1)$

$13 \mathrm{~mm}$ in 3 direction

Figure 15: DCB modelling overview, showing hinge modelling and boundary conditions.



Figure 16: Applied load versus displacement, Experimental Test and $2.5 \mathrm{~mm}$ model with PMs 1-4. 


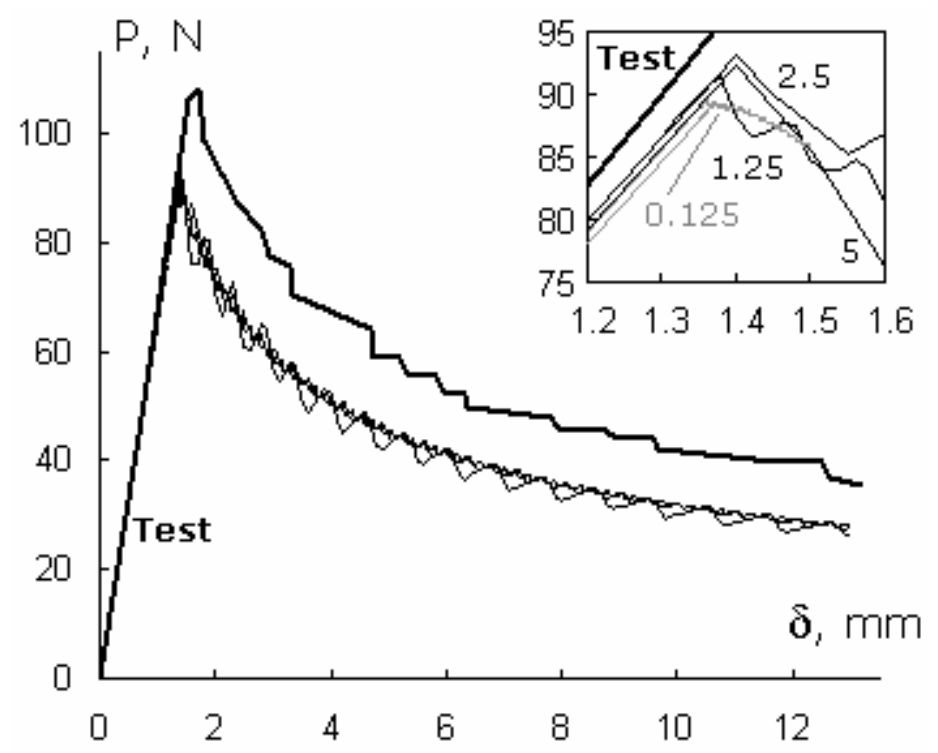

Figure 17: Applied load versus displacement, Experimental Test and PM 1 with $5 \mathrm{~mm}, 2.5$ $\mathrm{mm}, 1.25 \mathrm{~mm}$ and $0.125 \mathrm{~mm}$ models.

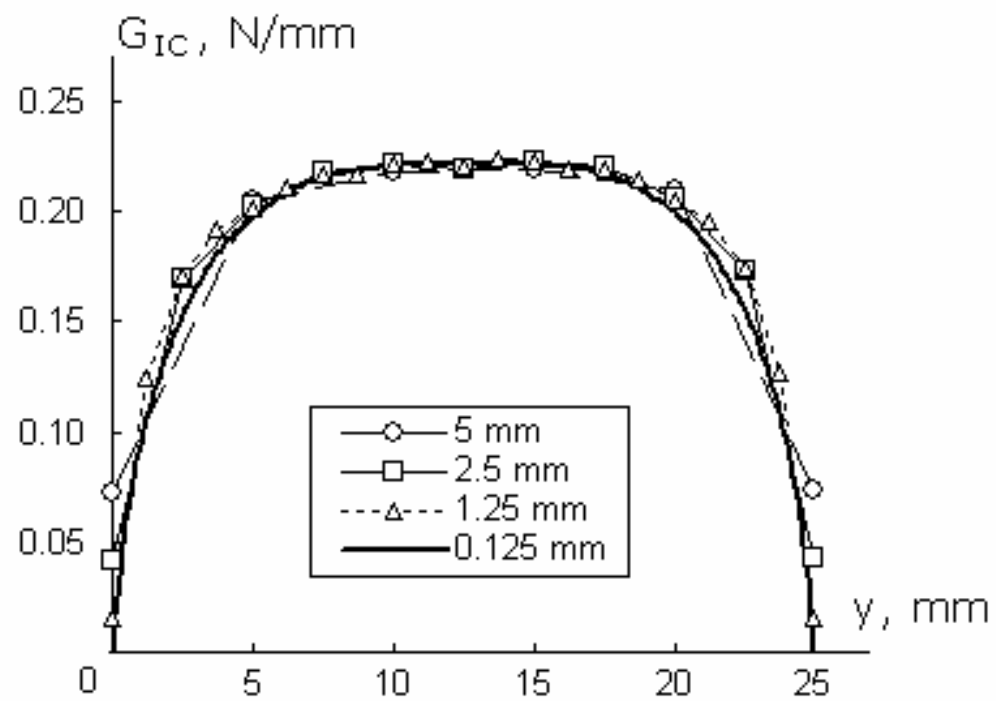

Figure 18: Strain energy release rate at $1.3 \mathrm{~mm}$ applied displacement (before crack growth), all FE models. 


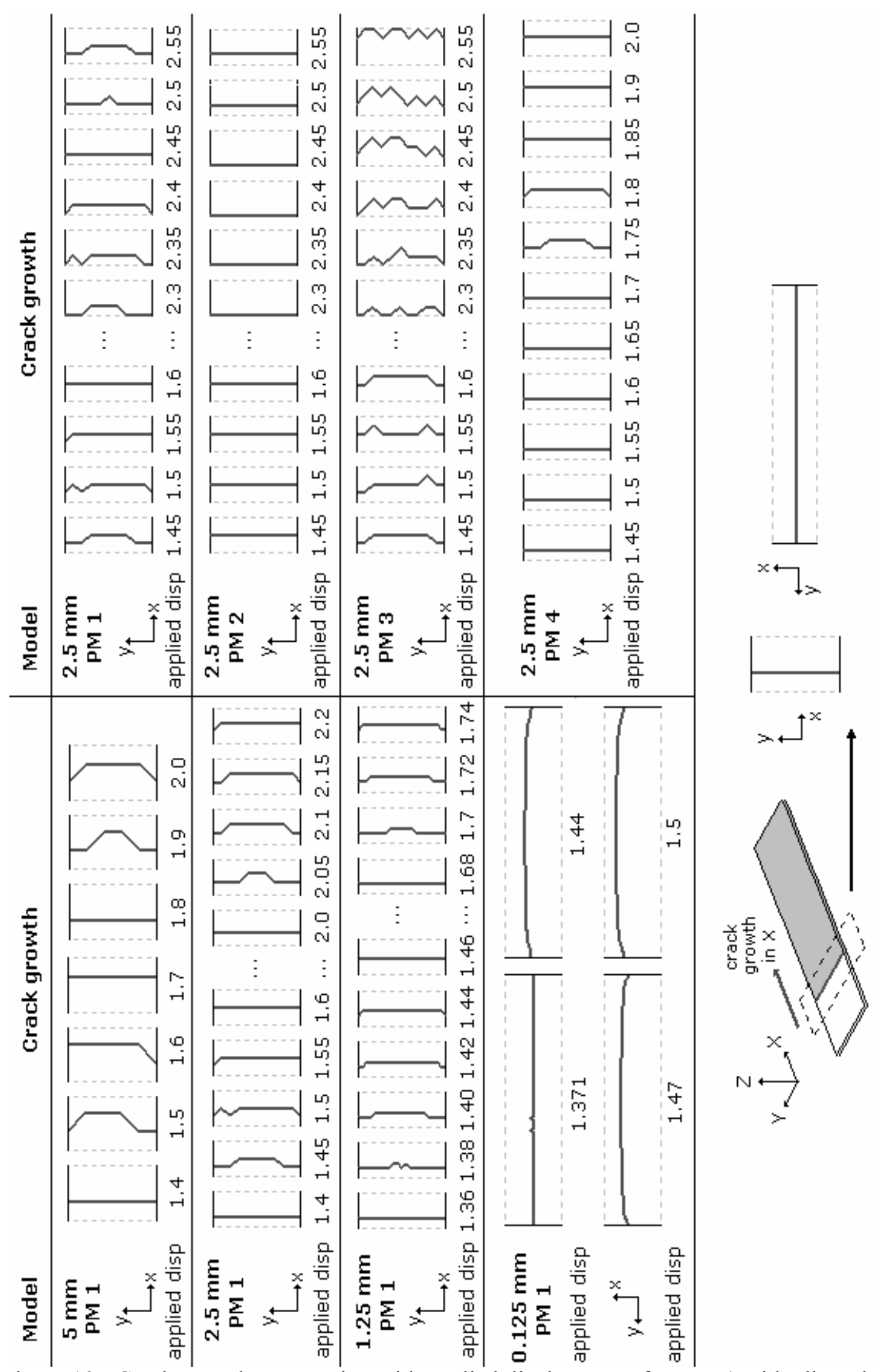

Figure 19: Crack growth progression with applied displacement for: PM 1 with all models, and; the $2.5 \mathrm{~mm}$ model with all propagation methods. 


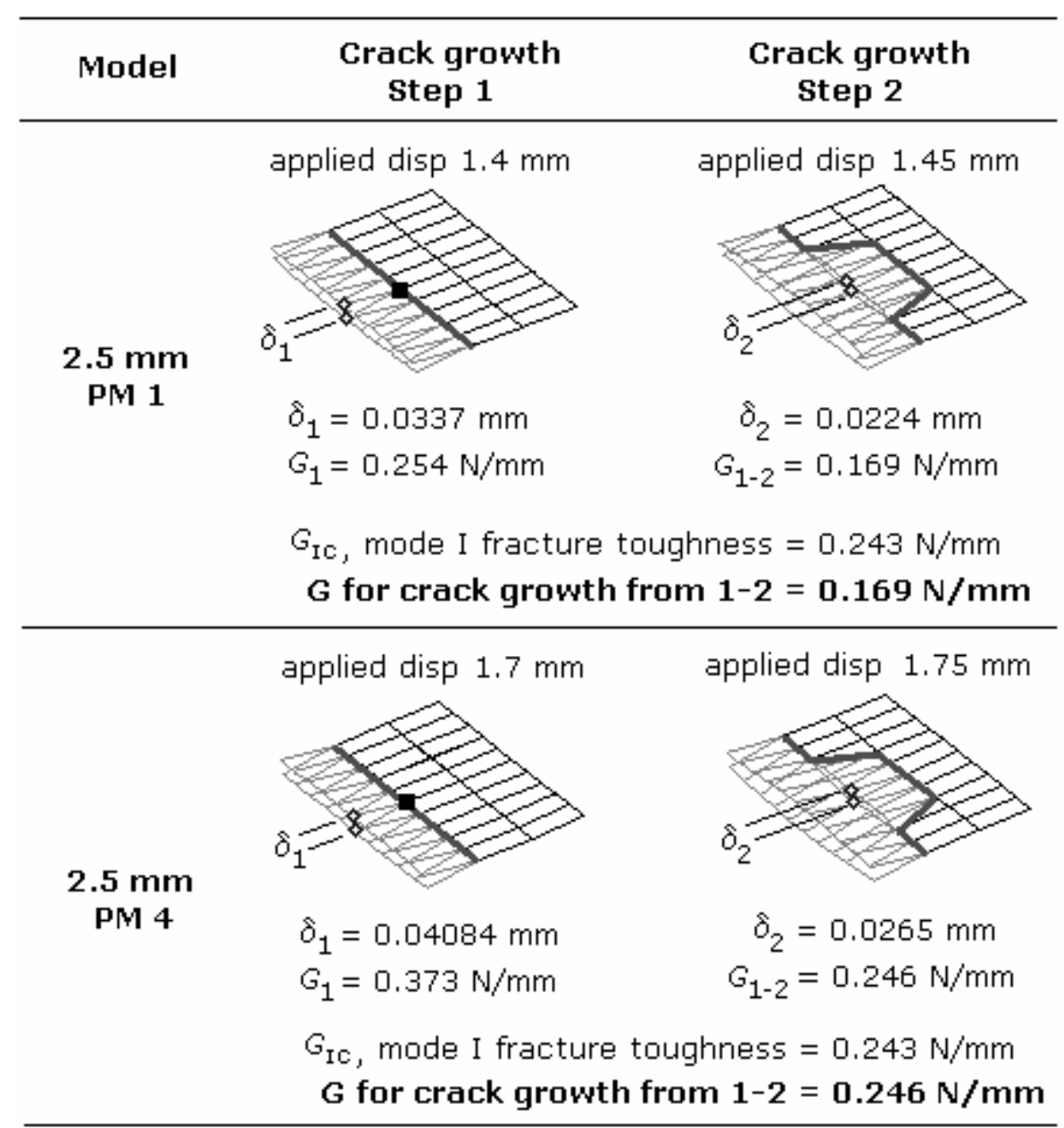

Figure 20: Crack growth initiation for PMs 1 and 4, showing the difference between assumed and actual strain energy release rates for both methods. 